ACCEPTED: BEHAVIORAL AND BRAIN SCIENCES (30/11/15)

THIS IS A PRE-PRINT (I.E. PRE-REVIEW) VERSION OF THE ACCEPTED MANUSCRIPT

ABSTRACT WORD COUNT: 51/60

MAIN TEXT WORD COUNT: 999/1000

REFERENCES WORD COUNT: 316

ENTIRE TEXT: 1451

Calling for a developmental perspective on action-based consciousness Hana D'Souza ${ }^{1,2}$ \& Andrew J. Bremner ${ }^{2}$

${ }^{1}$ Centre for Brain and Cognitive Development, Department of Psychological Sciences, Birkbeck, University of London, Malet Street, London, WC1E 7HX, UK. Tel: +44(0)20 7078 5129. Email: hana.dsouza@gmail.com.

${ }^{2}$ Sensorimotor Development Research Unit, Department of Psychology, Goldsmiths, University of London, New Cross, London, SE14 6NW, UK. Tel: +44 (0) 207078 5142. Email: a.bremner@gold.ac.uk

CORRESPONDENCE TO: Hana D’Souza, Centre for Brain and Cognitive Development, Department of Psychological Sciences, Birkbeck, University of London, Malet Street, London, WC1E 7HX, UK. Tel: +44(0)20 7078 5129. Email: hana.dsouza@gmail.com. 


\begin{abstract}
The human newborn can resolve some response conflicts in order to adapt their behaviour, suggesting that the newborn has consciousness according to Morsella et al.'s framework. We pose a range of developmental questions regarding Morsella et al.'s account, especially concerning the role of consciousness in the development of action.
\end{abstract}




\section{Calling for a developmental perspective on action-based consciousness}

Morsella and colleagues argue that consciousness comprises not higher order cognitive processes, but basic sensory components necessary for purposeful action. Whereas the development of higher order cognitive processes remains a matter of debate (e.g., Blakemore \& Choudhury, 2006; Zelazo, 2004), it is more accepted that the sensory constituents of action change substantially in early life as a result of the interplay between sensorimotor experience and brain development (Gibson \& Pick, 2000; Mareschal et al., 2007; Thelen \& Smith, 1996). Although it is unclear whether Morsella et al. view consciousness as a static or developmental phenomenon, all accounts of psychological functioning including those concerning consciousness are necessarily constrained by what we know of the developing organism. Thus, we believe that a consideration of development provides an important point of reference and validation for Morsella et al.’s proposal.

Morsella et al. propose that the function of consciousness is to allow the integration of intentional drives towards certain skeletal muscle outputs which are incompatible in a given situation. One example which they offer is that of holding one's breath under water - they view consciousness as a field in which the conflicting goals of being under water and the natural tendency to breathe are resolved. In their explanation of this position, Morsella et al. introduce "a hypothetical, simplified, human-like mammal that, though conscious [...], is not equipped with many of the complicated abilities/states associated with adult humans" (p. 7, italics added). A non-hypothetical organism already fits Morsella et al.'s description: the human newborn. 
We want Morsella et al. to replace their hypothetical "creature in the cave" with a human newborn for two reasons. Firstly, to examine whether their framework can describe real examples. Consciousness is likely to have a specific biological substrate working under different constraints to those of the "creature in the cave". Secondly, a consideration of developmental differences between newborn and (let's say) adult, and also the processes of development, will help test and extend their proposal. For instance, we can ask whether a human newborn automatically reacts to sensations one at a time or whether it is able to resolve response conflict for purposeful action. If it merely reacts to consecutive sensations, then one might argue that, according to Morsella et al.'s perspective, the newborn has no need for a conscious field, and thus consciousness may emerge gradually over development. However, as we shall see, the newborn can resolve some response conflicts in order to adapt their behaviour.

Although the newborn infant's ability to generate voluntary action is relatively limited, neonatal reflexes (Prechtl, 1993), traditionally viewed as automatic (outsideof-consciousness) stimulus reactions, have been argued by some to represent intentional actions (e.g., Rochat, 2001; von Hofsten, 2007). And thus we can ask whether behavioural reflexes in newborns can be modulated by competing intentions. The sucking reflex is activated whenever the nipple touches the back of the palate. This results in the jaw movements needed to induce milk flow (Prechtl, 1993). In fact, this behaviour is not completely reflexive; newborns can alter their sucking behaviour in response to the taste of the liquid (e.g., Crook, 1978). Salt solutions lead to shorter bursts of sucking in newborns, relative to distilled water. Morsella et al.'s conscious field permits contents about touch and taste to integrate and influence action, resulting 
in the infant modifying their sucking behaviour. Morsella's framework thus seems to indicate that human newborns are conscious.

Whilst newborns can modulate their sucking action in response to the salinity of the liquid, there have nonetheless been cases of accidental poisoning through excessive sodium intake following mistakes in food preparation (e.g., Finberg, Kiley, \& Luttrell, 1963). It seems that, in newborns, taste can only modify (not fully suppress) the sucking response, leading to continued ingestion of food even when distasteful. Nonetheless, infants are unlikely to be presented with dangerous liquid, so their sucking response is adaptively stronger than their reaction to the salinity of liquid. However, adults have better control over food intake: they are able to spit out distasteful food. Although both infant and adult behaviours are adaptive, we wonder whether the differences are due to developmental changes in consciousness. If they are, then an account of what changes in consciousness, and how it changes, is needed.

Morsella et al. propose that consciousness functions to provide a structure in which conflicting purposeful movements can be resolved. As such one can ask how the realisation of this function might change over development. Certainly the relevant movement conflicts change, and it takes time for infants to develop a well-structured behavioural repertoire which could form the mature "content" of Morsella et al.'s "conscious field". To take an example, months before infants are able to reach purposefully for an object, they spontaneously flap their arms when presented with it (Bhat \& Galloway, 2006). Over development, these spontaneous flapping movements come to more frequently contact objects, eventually leading to proficient goaldirected reaching. Considerable time is involved in these developments: Although in 
one waking hour the average toddler takes 2,368 steps, which is the equivalent length of 7.7 American football fields (Adolph et al., 2012), it is still several years before the movements they select in walking become adult-like (Adolph \& Robinson, 2015). What kind of role does Morsella et al.'s conscious field play in the development of competent purposeful action selection? In the example given above, do young infants' experiences of the conflict between representations of "spontaneous flapping" and "approaching an object" drive the development of proficient reaching?

To sum up our line of questioning, we wonder to what extent the conscious field is required for development or a result of development itself. Indeed, we had many questions concerning why Morsella et al. felt that consciousness was necessary to resolve the kinds of conflicts which the "creature in the cave" and the human newborn face. It might be that a developmental perspective could provide an answer to such queries, by highlighting the need for an ontogenetic mechanism by which we first come to resolve conflicts. 


\section{References}

Adolph, K. E., Cole, W. G., Komati, M., Garciaguirre, J. S., Badaly, D., Lingeman, J. M., Chan, G. L. Y., \& Sotsky, R. B. (2012). How do you learn to walk? Thousands of steps and dozens of falls per day. Psychological Science, 23, 1387-1394.

Adolph, K. E., Robinson, S. R. (2015). Motor development. In L. Liben \& U. Muller (Eds.), Handbook of child psychology and developmental science (7th ed., Vol. 2, pp. 114-157). New York: Wiley.

Bhat, A. N., \& Galloway, J. C. (2006). Toy-oriented changes during early arm movements: Hand kinematics. Infant Behavior and Development, 29, 358-372.

Blakemore, S. J., \& Choudhury, S. (2006). Development of the adolescent brain: implications for executive function and social cognition. Journal of Child Psychology and Psychiatry, 47, 296-312.

Crook, C. K. (1978). Taste perception in the newborn infant. Infant Behavior and Development, 1, 52-69.

Finberg, L., Kiley, J., \& Luttrell, C. N. (1963). Mass accidental salt poisoning in infancy: A study of a hospital disaster. JAMA, 184, 187-190.

Gibson, E. J., \& Pick, A. D. (2000). An ecological approach to perceptual learning and development. New York: Oxford University Press.

Mareschal, D., Johnson, M. H., Sirois, S., Spratling, M. W., Thomas, M. C. S., \& Westermann, G. (2007). Neuroconstructivism, Vol. 1: How the brain constructs cognition. Oxford: Oxford University Press.

Prechtl, H. F. R. (1993). Principles of early motor development in the human. In A. F. 
Kalverboer, B. Hopkins, \& R. Geuze (Eds.), Motor development in early and later childhood: Longitudinal approaches (pp. 35-50). Cambridge: Cambridge University Press.

Rochat, P. (2001). The infant's world. Cambridge, MA: Harvard University Press.

Thelen, E., \& Smith, L. B. (1996). A dynamic systems approach to the development of cognition and action. Cambridge, MA: MIT Press.

von Hofsten, C. (2007). Action in development. Developmental Science, 10, 5460.

Zelazo, P. D. (2004). The development of conscious control in childhood. Trends in Cognitive Sciences, 8, 12-17. 